\title{
Cadmium-induced disruption in 24-h expression of clock and redox enzyme genes in rat medial basal hypothalamus: prevention by melatonin
}

\author{
Vanesa Jiménez-Ortega ${ }^{1}$, Pilar Cano-Barquilla ${ }^{1}$, Pablo A. Scacchi ${ }^{2,3}$, Daniel P. Cardinali ${ }^{2,3 *}$ and \\ Ana I. Esquifino ${ }^{1}$
}

1 Departamento de Bioquímica y Biología Molecular III, Universidad Complutense, Facultad de Medicina, Spain

${ }^{2}$ Departamento de Docencia e Investigación, Pontificia Universidad Católica Argentina, Facultad de C Médicas, Argentina

${ }^{3}$ Departamento de Fisiología, Universidad de Buenos Aires, Facultad de Medicina, Argentina

\section{Edited by:}

Oscar Prospéro-García, Universidad

Nacional Autónoma de México,

Mexico

Reviewed by:

Diego A. Golombek, Universidad Nacional de Quilmes, Argentina Raul Aguilar-Roblero, Universidad Nacional Autónoma de México, Mexico

\section{*Correspondence:}

Daniel P. Cardinali, Facultad de Ciencias Médicas, Departamento de Docencia e Investigación, Pontificia Universidad Católica Argentina, Avenida Alicia Moreau de Justo 1500 $4^{\circ}$ Piso, 1107 Buenos Aires, Argentina. e-mail:danielcardinali@uca.edu.ar; danielcardinali@fibertel.com.ar
In a previous study we reported that a low daily p.o. dose of cadmium (Cd) disrupted the circadian expression of clock and redox enzyme genes in rat medial basal hypothalamus $(\mathrm{MBH})$. To assess whether melatonin could counteract $\mathrm{Cd}$ activity, male Wistar rats (45 days of age) received $\mathrm{CdCl}_{2}(5 \mathrm{ppm})$ and melatonin $(3 \mu \mathrm{g} / \mathrm{mL})$ or vehicle $(0.015 \%$ ethanol) in drinking water. Groups of animals receiving melatonin or vehicle alone were also included. After 1 month, MBH mRNA levels were measured by real-time PCR analysis at six time intervals in a 24-h cycle. In control MBH Bmal1 expression peaked at early scotophase, Per1 expression at late afternoon, and Per2 and Cry2 expression at mid-scotophase, whereas neither Clock nor Cry1 expression showed significant 24-h variations. This pattern was significantly disrupted (Clock, Bmal1) or changed in phase (Per1, Per2, Cry2) by $\mathrm{CdCl}_{2}$ while melatonin counteracted the changes brought about by $\mathrm{Cd}$ on Per1 expression only. In animals receiving melatonin alone the 24-h pattern of $\mathrm{MBH}$ Per2 and Cry2 expression was disrupted. $\mathrm{CdCl}_{2}$ disrupted the 24-h rhythmicity of $\mathrm{Cu} / \mathrm{Zn}$ - and $\mathrm{Mn}$-superoxide dismutase (SOD), nitric oxide synthase (NOS)-1, NOS-2, heme oxygenase (HO)-1, and HO-2 gene expression, most of the effects being counteracted by melatonin. In particular, the co-administration of melatonin and $\mathrm{CdCl}_{2}$ increased $\mathrm{Cu} / \mathrm{Zn}-\mathrm{SOD}$ gene expression and decreased that of glutathione peroxidase (GPx), glutathione reductase (GSR), and HO-2. In animals receiving melatonin alone, significant increases in mean $\mathrm{Cu} / \mathrm{Zn}$ and $\mathrm{Mn}-\mathrm{SOD}$ gene expression, and decreases in that of GPx, GSR, NOS-1, NOS-2, HO-1, and HO-2, were found. The results indicate that the interfering effect of melatonin on the activity of a low dose of $\mathrm{CdCl}_{2}$ on $\mathrm{MBH}$ clock and redox enzyme genes is mainly exerted the level of redox enzyme gene expression.

Keywords: cadmium, melatonin, circadian rhythms, clock genes, redox enzyme genes, medial basal hypothalamus

\section{INTRODUCTION}

Cadmium (Cd), a heavy metal, is present in soils, sediments, air, and water. Unlike most metals, Cd use began fairly recently with its large-scale application dating from 1940s. Today its main uses are for nickel-cadmium battery manufacture, pigments, and plastic stabilizers (WHO, 1995).

Cadmium in soil and water is taken up by plants and is concentrated and transferred to upper links of the food chain, including humans (WHO, 1995; Satarug et al., 2003). Due to the long biological half-life of $\mathrm{Cd}$ (i.e., 10-30 years) its accumulation in the body can increase the risk of toxicity (Sugita and Tsuchiya, 1995). The principal determinants of human Cd exposure are smoking habits, diet, and to a certain extent, occupational exposure, like that occurring in non-ferrous metal smelters, in the production and processing of $\mathrm{Cd}$ alloys and compounds and, increasingly, in the recycling of electronic waste. Non-occupational exposure is mainly from cigaret smoke which contains relatively high concentrations of this element. According to WHO (Wakabayashi et al.,
1987) one cigaret (containing $0.5-3 \mu \mathrm{g} \mathrm{Cd} / \mathrm{g}$ of tobacco) can result in up to $3 \mu \mathrm{g}$ daily $\mathrm{Cd}$ absorption via the lungs. Chronic exposure to these low doses of $\mathrm{Cd}$ causes neuroendocrine and neurobehavioral disturbances in animals and humans (Viaene et al., 2000; Lafuente et al., 2003, 2004, 2005; Leret et al., 2003).

At a high concentration $\mathrm{Cd}$ increases oxidative damage in the rodent brain (Lopez et al., 2006; Yang et al., 2007). Less information is available on the mediation by redox mechanisms of brain effects of a low concentration of Cd. In a recent study we examined the effect of a low dose of Cd ( $7.5 \mu \mathrm{g} /$ day $)$ on 24 -h changes in expression of redox pathway enzyme and circadian genes in rat medial basal hypothalamus (MBH; Jiménez-Ortega et al., 2010). In $\mathrm{CdCl}_{2}$-treated rats a disruption of 24-h pattern of $\mathrm{MBH}$ gene expression of nitric oxide synthase (NOS)-1 and -2, heme oxygenase (HO)-1 and -2, Mn-superoxide dismutase (Mn-SOD), catalase, glutathione peroxidase (GPx), and glutathione reductase (GSR) was detectable. Mean 24-h levels of MBH mRNA for HO2, Mn-SOD, and catalase augmented after Cd intake (presumably 
as a compensatory increase caused by the augmented oxidative load), whereas those of NOS-2 decreased (presumably because $\mathrm{Cd}$ causes toxicity independently of NO formation; Wright and Baccarelli, 2007). After $\mathrm{CdCl}_{2}$ intake, the 24 -h pattern of clock gene expression in $\mathrm{MBH}$ seen in control rats was significantly disrupted, suggesting that a primary mechanism of action could be on circadian clock mechanisms (Jiménez-Ortega et al., 2010).

Melatonin, the major secretory product of the pineal gland, is released every day at night. In addition, melatonin is also locally synthesized in various cells, tissues, and organs including lymphocytes, human and murine bone marrow, the thymus, the gastrointestinal tract, skin, and the eyes where it plays either an autocrine or paracrine role (see for reference, Pandi-Perumal et al., 2006; Reiter et al., 2009; Hardeland et al., 2011). Both in animals and in humans, melatonin participates in diverse physiological functions signaling not only the length of the night (the chronobiotic effect; Dawson and Armstrong, 1996; Arendt and Skene, 2005) but also enhancing free radical scavenging, the immune response and cytoprotection (Hardeland et al., 2011).

The objective of the present study was to examine the putative chronobiotic-cytoprotective role of melatonin on Cd-induced changes in clock gene and redox enzyme gene expression in rat $\mathrm{MBH}$. We also wished to assess whether the concomitant administration of melatonin could modify 24 -h expression of $\mathrm{MBH}$ redox enzyme genes in a way compatible with the recently reported activity of melatonin on the same set of enzymes (Jiménez-Ortega et al., 2009).

\section{MATERIALS AND METHODS \\ ANIMALS AND EXPERIMENTAL DESIGN}

Male Wistar rats ( 45 days of age, $n=169$ ) were maintained under standard conditions with controlled light (12:12 h light/dark schedule; lights on at $0800 \mathrm{~h})$ and temperature $\left(22 \pm 2^{\circ} \mathrm{C}\right)$. The rats received $\mathrm{CdCl}_{2}(5 \mathrm{ppm})$ and melatonin $(3 \mu \mathrm{g} / \mathrm{mL})$ or vehicle in drinking water for 1 month. Two groups given melatonin or vehicle in tap water were also included. Food and water were supplied ad libitum. The stock solution of melatonin was prepared in $50 \%$ ethanol; final ethanol concentration in drinking water was $0.015 \%$. Cd-administered animals and vehicle-treated controls received $0.015 \%$ ethanol in drinking water. Since rats drank about $20 \mathrm{~mL} /$ day with $90-95 \%$ of this total daily water taken up during the dark period, the melatonin dosage used provided approximately $60 \mu \mathrm{g}$ melatonin/day. This dose was 10 timed higher than that needed to obtain physiological circulating melatonin levels in pinealectomized rats (Cardinali et al., 2004). Nocturnal water consumption did not differ among the experimental groups.

After 1 month groups of six to eight rats were sacrificed by decapitation under conditions of minimal stress at six different time intervals, every $4 \mathrm{~h}$ throughout a 24 -h cycle, starting at $0900 \mathrm{~h}$. At night intervals animals were killed under red dim light. The brains were rapidly removed and the $\mathrm{MBH}$ including the median eminence was quickly dissected out following the landmarks of Szentagothai et al. (1968). The MBH consisted of a 3-mm-thick block of tissue weighing 4-6 mg and extending from the rostral border of the optic chiasm to the rostral margin of the mammillary bodies, and laterally to the hypothalamic sulci (Moreno et al., 1992).
Samples were kept frozen at $-70^{\circ} \mathrm{C}$ until further assayed. The care and use as well as all procedures involving animals were approved by the Institutional Animal Care Committee, Faculty of Medicine, Complutense University, Madrid. The study was in accordance with the guidelines of the Institutional Care and Use Committee of the National Institute on Drug Abuse, National Institutes of Health and the Guide for the Care and Use of Laboratory Animals (Institute of Laboratory Animal Resources, 1996).

\section{REAL-TIME QUANTITATIVE POLYMERASE CHAIN REACTION}

Total RNA extraction was performed using the RNeasy protect mini kit and was analyzed using QuantiTec SYBR green kit (Qiagen, Hielden, Germany). The iScript ${ }^{\mathrm{TM}}$ cDNA Synthesis Kit (BioRad Laboratories SA, Madrid) was used to synthesize cDNA from $1 \mu \mathrm{g}$ of total RNA, according to the manufacturer's protocol. The house keeping gene $\beta$-actin was used as a constitutive control for normalization.

Reactions were carried out in the presence of $200 \mathrm{nM}$ of specific primers for Clock, Bmal1, Per1, Per2, Cry1, and Cry2, NOS-1, NOS-2, HO-1, HO-2, Cu/Zn-SOD, Mn-SOD, catalase, GPx, and GSR. Primers were designed using Primer3 software (The Whitehead Institute, http://frodo.wi.mit.edu/cgibin/primer3/primer3_www.cgi) and are shown in Table 1.

Polymerase chain reactions (PCR) were carried out in an Eppendorf RealPlex Mastercycler (Eppendorf AG, Hamburg, Germany). The real-time quantitative PCR (qPCR) program included a $94^{\circ} \mathrm{C}$ enzyme activation step for $2 \mathrm{~min}$ followed by 40 cycles of $95^{\circ} \mathrm{C}$ denaturation for $15 \mathrm{~s}, 60^{\circ} \mathrm{C}$ annealing for $30 \mathrm{~s}$ and $72^{\circ} \mathrm{C}$ extension for $30 \mathrm{~s}$. Detection of fluorescent product was carried out at the end of the $72^{\circ} \mathrm{C}$ extension period.

Serial dilutions of cDNA from control $\mathrm{MBH}$ were used to perform calibration curves in order to determine amplification efficiencies. For the primers used there were no differences between transcription efficiencies, the amount of initial cDNA in each sample being calculated by the $2^{-\Delta \Delta C t}$ method (Livak and Schmittgen, 2001). All samples were analyzed in triplicate and in three different measures. Fractional cycle at which the amount of amplified target becomes significant $(\mathrm{Ct})$ was automatically calculated by the PCR device.

To estimate whether treatment or time of day modified the expression of $\beta$-actin, in MBH PCR with serial dilutions of this housekeeping gene was performed. In this study Ct did not vary significantly as a function of treatment or of time of day, indicating the validity to employ $\beta$-actin as a housekeeping gene. It must be noted that in a previous study on $\beta$-actin expression in a larger hypothalamic block than that used herein, which weighed 42 $63 \mathrm{mg}$ and included the preoptic, suprachiasmatic, paraventricular, supraoptic, arcuate, dorsomedial, ventromedial, and mammillary areas and the median eminence revealed time of day changes with maxima at $0800 \mathrm{~h}$ (Iovanna et al., 1990).

\section{DATA ANALYSIS}

After verifying normality of distribution of data in a normal distribution probability plot, the statistical analysis of the results was performed by a one-way or a two-way factorial analysis of variance (ANOVA) followed by Bonferroni's multiple comparison 
Table 1 | Sequence of the primers used for real-time PCR.

\begin{tabular}{|c|c|c|c|}
\hline \multirow{3}{*}{$\begin{array}{l}\text { Gene } \\
\beta \text {-Actin }\end{array}$} & \multicolumn{2}{|r|}{ Primers } & \multirow{2}{*}{\begin{tabular}{|l} 
Product size (bp \\
99
\end{tabular}} \\
\hline & Forward & ctctcttccagccttccttc & \\
\hline & Backward & ggtctttacggatgtcaacg & \\
\hline \multirow[t]{2}{*}{ Clock } & Forward & tgccagctcatgagaagatg & 98 \\
\hline & Backward & catcgctggctgtgttaatg & \\
\hline \multirow[t]{2}{*}{ Bmal1 } & Forward & ccgtggaccaaggaagtaga & 102 \\
\hline & Backward & ctgtgagctgtgggaaggtt & \\
\hline \multirow[t]{2}{*}{ Per1 } & Forward & ggctccggtacttctctttc & 106 \\
\hline & Backward & aataggggagtggtcaaagg & \\
\hline \multirow[t]{2}{*}{ Per2 } & Forward & acacctcatgagccagacat & 99 \\
\hline & Backward & ctttgactcttgccactggt & \\
\hline \multirow[t]{2}{*}{ Cry1 } & Forward & cagttgcctgtttcctgacc & 91 \\
\hline & Backward & cagtcggcgtcaagcagt & \\
\hline \multirow[t]{2}{*}{ Cry2 } & Forward & attgagcggatgaagcagat & 103 \\
\hline & Backward & ccacagggtgactgaggtct & \\
\hline \multirow[t]{2}{*}{ NOS-1 } & Forward & atcggcgtccgtgactactg & 92 \\
\hline & Backward & tcctcatgtccaaatccatcttcttg & \\
\hline \multirow[t]{2}{*}{ NOS-2 } & Forward & tggcctccctctggaaaga & 93 \\
\hline & Backward & ggtggtccatgatggtcacat & \\
\hline \multirow[t]{2}{*}{ HO-1 } & Forward & tgctcgcatgaacactctg & 123 \\
\hline & Backward & tcctctgtcagcagtgcc & \\
\hline \multirow[t]{2}{*}{$\mathrm{HO}-2$} & Forward & agcaaagttggccttaccaa & 84 \\
\hline & Backward & gtttgtgctgccctcacttc & \\
\hline \multirow[t]{2}{*}{$\mathrm{Cu} / \mathrm{Zn}-\mathrm{SOD}$} & Forward & ggtggtccacgagaaacaag & 98 \\
\hline & Backward & caatcacaccacaagccaag & \\
\hline \multirow[t]{2}{*}{ Mn-SOD } & Forward & aaggagcaaggtcgcttaca & 94 \\
\hline & Backward & acacatcaatccccagcagt & \\
\hline \multirow[t]{2}{*}{ Catalase } & Forward & gaatggctatggctcacaca & 100 \\
\hline & Backward & caagttttgatgccctggt & \\
\hline \multirow[t]{2}{*}{ GPx1 } & Forward & tgcaatcagttcggacatc & 120 \\
\hline & Backward & cacctcgcacttctcaaaca & \\
\hline \multirow[t]{2}{*}{ GSR } & Forward & atcaaggagaagcgggatg & 96 \\
\hline & Backward & gcgtagccgtggatgactt & \\
\hline
\end{tabular}

tests, as stated. $P$ values lower than 0.05 were considered evidence for statistical significance.

\section{RESULTS}

The effect of Cd and/or melatonin on 24-h pattern of MBH mRNA levels of the circadian clock genes examined is depicted in Figure 1. In control rats, $\mathrm{MBH}$ mRNA levels of Bmall attained maximal values at the beginning of scotophase followed by a nadir at the middle of the phase and a second increase at the end $(p<0.01)$. $\mathrm{MBH}$ Per1 expression peaked at later afternoon during photophase $(p<0.01)$ while Cry2 expression showed maxima during the scotophase $(p<0.03)$. Two maxima (at the middle of photophase and at the beginning and middle of scotophase) were seen in the case of mRNA Per2 levels ( $p<0.01$; Figure 1). Neither Clock nor Cry1 expression exhibited significant 24 -h variations.

$\mathrm{CdCl}_{2}$ treatment significantly suppressed circadian rhythmicity in Bmal1 expression, changed the phase of Per1, Per2, and Cry2 expression and induced a late photophase peak in Clock expression $(p<0.01)$. The concomitant administration of melatonin counteracted the changes in 24-h pattern of Per1 expression caused by Cd, whereas it did not affect significantly other changes found with Cd (as for Clock, Per2, and Cry2 expression) or induced new maxima (as for Bmal1 or Cry1 expression; Figure 1). In animals receiving melatonin alone the 24 -h pattern in expression of $\mathrm{MBH}$ Per2 and Cry2 was significantly disrupted $(p<0.01)$, while that of Clock, Bmal1, Per1, and Cry1 remained unchanged (Figure 1).

Figures 2 and 4 summarize the effect of treatment on 24-h pattern and mean levels of MBH mRNA of the redox enzymes examined. Control rats exhibited significant daily variations in $\mathrm{MBH}$ expression of $\mathrm{Cu} / \mathrm{Zn}-\mathrm{SOD}, \mathrm{Mn}-\mathrm{SOD}$, catalase, GPx, NOS-2, $\mathrm{HO}-1$, and HO-2 genes (Figures 2 and 3). $\mathrm{CdCl}_{2}$ administration phase-delayed Mn-SOD gene expression and suppressed the maximum in gene expression of GPx seen at midday $(p<0.03$; Figure 2). $\mathrm{CdCl}_{2}$ also affected the 24 -h pattern of expression of $\mathrm{MBH}$ NOS and $\mathrm{HO}$ isoenzymes by inducing maxima at late scotophase (NOS-1), at midday and late scotophase (NOS-2), at midday, early and late scotophase (HO-1), and at early morning (HO-2; Figure 3).

The concomitant administration of melatonin reversed the phase delay in $\mathrm{Mn}-\mathrm{SOD}$ gene expression given by $\mathrm{CdCl}_{2}$ $(p<0.001$; Figure 2) and counteracted the effect of Cd on $24 \mathrm{~h}$ pattern in expression of NOS and HO isoenzymes $(p<0.02$; Figure 3). Melatonin $+\mathrm{CdCl}_{2}$ administration disrupted the 24- $\mathrm{h}$ pattern of $\mathrm{Cu} / \mathrm{Zn}$-SOD gene expression by inducing a late scotophase peak ( $p<0.02$; Figure 2$)$. In animals receiving melatonin alone, suppression of 24-h rhythmicity in gene expression $(\mathrm{Cu} / \mathrm{Zn}$ SOD, HO-2) and induction of a mid-scotophase (GSR) or early morning peak of expression (NOS-1, NOS-2, HO-1) were found $(p<0.01$; Figures 2 and 3$)$.

Figure 4 depicts the mean 24-h values for gene expression of $\mathrm{MBH}$ redox enzymes in the four groups of animals studied. A factorial ANOVA on the effects of treatment on mean gene expression indicated that $\mathrm{CdCl}_{2}$ administration increased significantly MnSOD, catalase, and HO-2 expression and decreased that of NOS-2 gene. The concomitant administration of melatonin reversed the effect of Cd on mean catalase, NOS-2, and HO-2 gene expression, augmented 24-h mean values of $\mathrm{Cu} / \mathrm{Zn}$ - and $\mathrm{Mn}-\mathrm{SOD}$ mRNA levels and decreased those of GPx, GSR, and HO-1. In animals receiving melatonin alone, significant increases in mean $\mathrm{Cu} / \mathrm{Zn}$ and Mn-SOD gene expression, and decreases in that of GPx, GSR, NOS-1, NOS-2, HO-1, and HO-2, were found (Figure 4).

\section{DISCUSSION}

The mammalian circadian timing system comprises oscillators found in almost every cell of the body together with a central rhythm generator located in the hypothalamic suprachiasmatic nuclei (SCN; Lincoln et al., 2006). At the cell level, circadian rhythms are driven by the self-regulatory interaction of a set of clock genes and their protein products (Levi et al., 2010). The positive drive to the daily clock is constituted by helix-loop-helix, PAS-domain containing transcription factor genes, called Clock and Bmal1 (or its paralog Npas2). The protein products of these genes form heterodimeric complexes that control the transcription of other clock genes, notably Period (Per1/Per2/Per3) genes, and Cryptochrome $(\mathrm{Cr} y 1 / \mathrm{Cr} y 2)$ genes, which in turn provide the negative feedback signal that shuts down the Clock/Bmall drive to complete the circadian cycle. Other clock genes like 

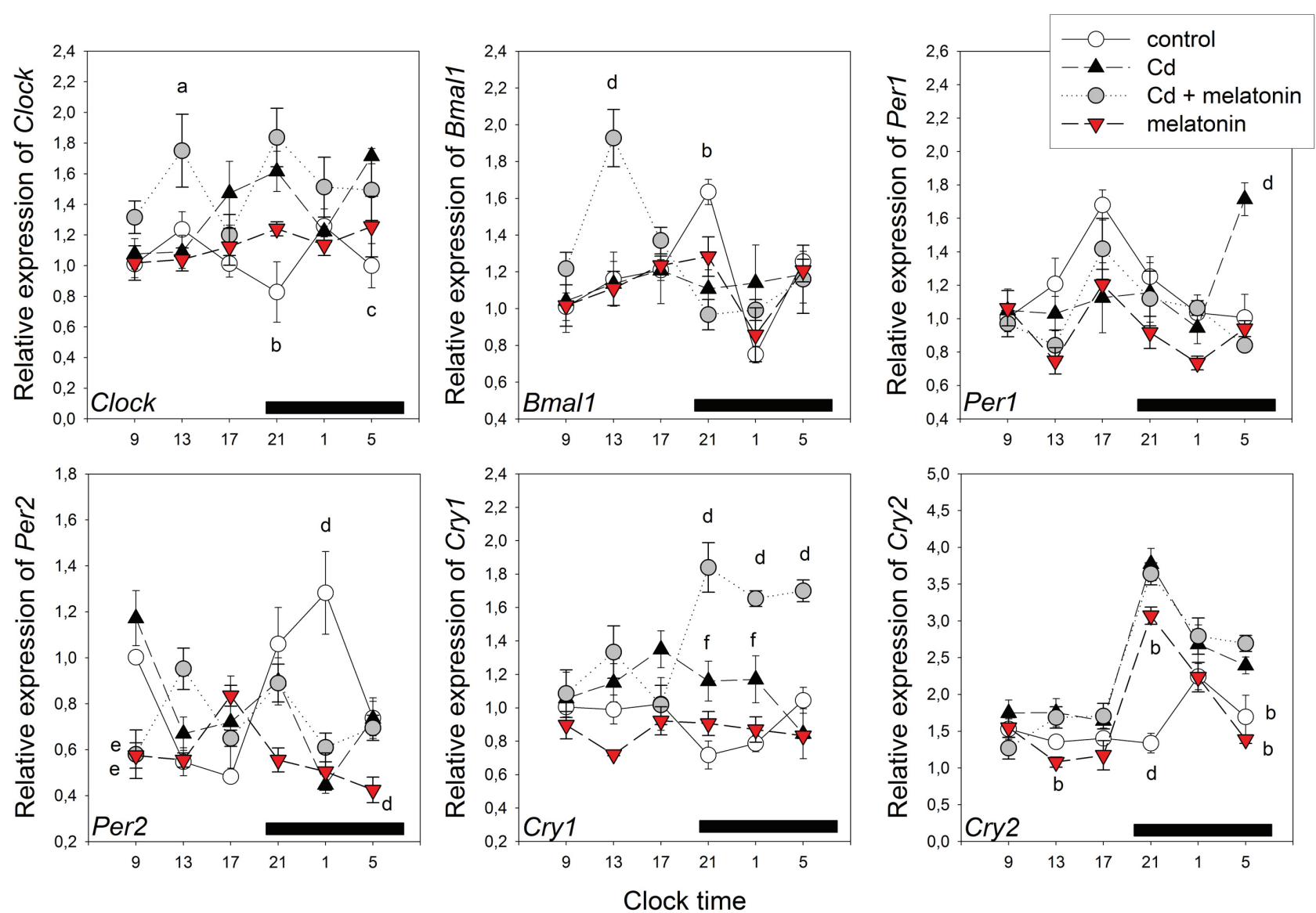

FIGURE 1 | Effect of melatonin on Cd-induced changes in 24-h pattern in expression of Clock, Bmal1, Per1, Per2, Cry1, and Cry2 in rat MBH. The rats received $\mathrm{CdCl}_{2}(5 \mathrm{ppm})$ and melatonin $(3 \mu \mathrm{g} / \mathrm{mL})$ or vehicle in drinking water for 1 month. Two groups given melatonin or vehicle in tap water were also included. Groups of six to eight rats were killed by decapitation at six different time intervals throughout a 24-h cycle. mRNA levels encoding the clock genes were measured as described in the text. Shown are the mean \pm SEM of $m R N A$ determination as measured by triplicate real-time PCR analyses of RNA samples. Letters denote significant differences in a one-way ANOVA followed by a Bonferroni's multiple comparison test performed at every time interval, as follows: ${ }^{a} p<0.05$ vs. $\mathrm{Cd}$ and melatonin groups; ${ }^{b} p<0.02$ vs. $\mathrm{Cd}$ and $\mathrm{Cd}+$ melatonin groups;
${ }^{c} p<0.05$ vs. $C d ;{ }^{d} p<0.01$ vs. the remaining groups; ${ }^{e} p<0.01$ vs. $C d$ and control groups; ${ }^{\dagger} p<0.05$ vs. control. One-way ANOVAs within each experimental group indicated significant time-related changes in clock gene expression as follows: Controls: Bmal1, Per1, Per2, and Cry2 $(F=11.3$, $p<0.0001, F=2.54, p<0.04, F=7.94, p<0.001$, and $F=3.41, p<0.03$, respectively). Cd: Clock, Per1, Per2, and Cry2 ( $F=4.71, p<0.008$, $F=4.12, p<0.01, F=5.84, p<0.03$, and $F=19.1, p<0.0001$, respectively). Cd + melatonin: Bmal1, Per1, Per2, Cry1, and Cry2 ( $F=10.1$, $p<0.0001, F=3.11, p<0.04, F=4.48, p<0.009, F=7.82, p<0.001$, and $F=19.6, p<0.0001$, respectively. Melatonin: Per2 and Cry2 $(F=14.2$ and 50.8, $p<0.0001$, respectively). For further statistical analysis see text.
Rev-erb $\alpha$, Ror $\alpha, N R 1 D 1$, or timeless provide additional transcriptional/translational feedback loops to form the rest of the core clockwork (Levi et al., 2010), which has been characterized in rodents by a transgenic gene deletion methodology.

A major question concerns as about how the circadian apparatus is adjusted to maintain coordination between physiology and the changing environment. Models including the relation between the redox state and the circadian clockwork have been proposed (Rutter et al., 2002). In zebrafish, light, as a key entraining stimulus for the circadian clock, induces the production of hydrogen peroxide that acts as the second messenger coupling photoreception to the circadian clock, as shown by the induction of $z$ Cryla and $z$ Per 2 genes and the subsequent circadian oscillation of $z$ Per 1 . In Z3 cells (Hirayama et al., 2007). These findings support a link between the regulation circadian clock genes and the control of cellular redox state (Rutter et al., 2002).

The present study aimed to examine the relations between circadian clock gene expression and gene expression of redox enzymes in a complex, heterogeneous brain area like the $\mathrm{MBH}$ of rats receiving a low dose of $\mathrm{CdCl}_{2}$ and/or melatonin. In the $\mathrm{MBH}$ of control rats expression of Bmall peaked at early scotophase, Per1 at late afternoon, and Per2 and Cry2 at mid-scotophase, whereas neither Clock nor Cry1 expression showed significant 24$\mathrm{h}$ variations. Presumably, the nuclear heterogeneity of the $\mathrm{MBH}$ fragments employed precluded identification of the reciprocal relationship between Clock/Bmall and Per1/Per2 expression seen in isolated nuclei, like the SCN (Poirel et al., 2003; Agez et al., 2007; Challet, 2007). 

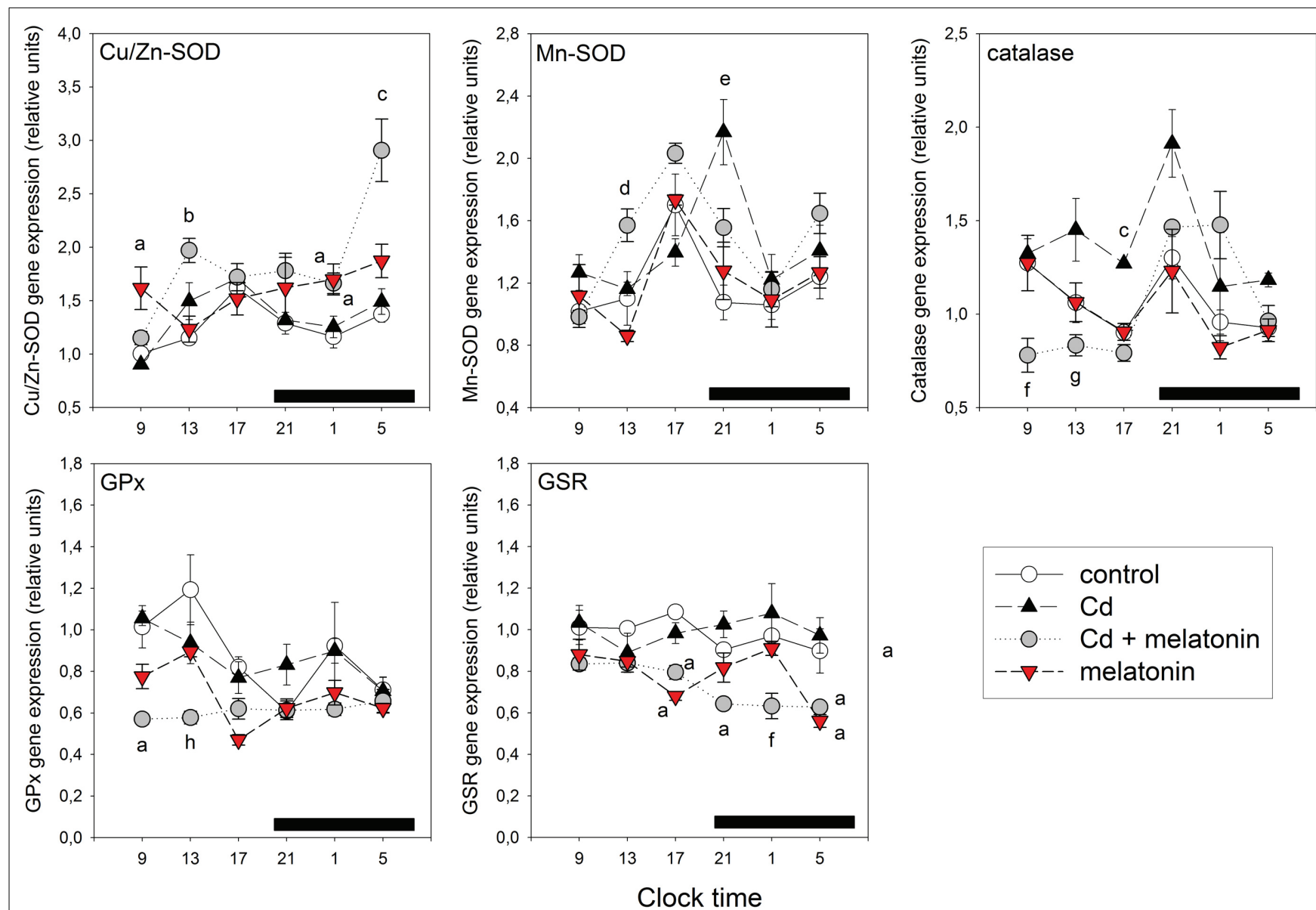

FIGURE 2 | Effect of melatonin on Cd-induced changes in 24-h pattern in expression of mRNA for $\mathrm{Cu} / \mathrm{Zn}$-SOD, Mn-SOD, catalase, Gpx, and GSR in rat $\mathbf{M B H}$. For experimental details see legend to Figure 1. mRNA levels encoding the enzymes were measured as described in the text. Shown are the mean \pm SEM of mRNA determination as measured by triplicate real-time PCR analyses of RNA samples. Letters denote significant differences in a one-way ANOVA followed by a Bonferroni's multiple comparison test performed at every time interval, as follows: ${ }^{a} p<0.02$ vs. $\mathrm{Cd}$ and control groups; ${ }^{b} p<0.05$ vs. melatonin and control groups; ${ }^{c} p<0.01$ vs. the remaining groups; ${ }^{\mathrm{d}} p<0.05$ vs. melatonin and $\mathrm{Cd}$ groups; ${ }^{e} p<0.05$ vs. melatonin and control groups; ${ }^{f} p<0.05$ vs. the remaining groups; ${ }^{9} p<0.01$ vs. $\mathrm{Cd} ;{ }^{h} p<0.02$ vs. control; One-way ANOVAs within each experimental group indicated significant time-related changes in enzyme gene expression as follows: Controls: $\mathrm{Cu} / \mathrm{Zn}-\mathrm{SOD}, \mathrm{Mn}-\mathrm{SOD}$, catalase, and $\mathrm{GPx}(F=6.21$, $p<0.002, F=3.33, p<0.03, F=3.17, p<0.04$, and $F=2.98, p<0.04$, respectively). Cd: $\mathrm{Cu} / \mathrm{Zn}-\mathrm{SOD}$ and $\mathrm{Mn}-\mathrm{SOD}(F=6.25, p<0.002$, and $F=7.01$, $p<0.001$, respectively). $\mathrm{Cd}+$ melatonin: $\mathrm{Cu} / \mathrm{Zn}-\mathrm{SOD}, \mathrm{Mn}-\mathrm{SOD}$, catalase, and GSR $(F=14.1, p<0.0001, F=15.5, p<0.0001, F=10.8, p<0.0001$, and $F=8.24, p<0.0001$, respectively). Melatonin: Mn-SOD, catalase, GPx, and GSR $(F=4.49, p<0.002, F=2.46, p<0.05, F=15.9, p<0.0001$, and $F=8.35, p<0.0001$, respectively). For further statistical analysis, see text.
As shown previously (Jiménez-Ortega et al., 2010), a low amount of $\mathrm{CdCl}_{2}$ (i.e., $5 \mathrm{ppm}$ in tap water, about $7.5 \mu \mathrm{g} /$ day) significantly suppressed (Bmal1) or disrupted 24-h pattern of expression (Per1, Per2, Cry2) while in the case of Clock significant 24 -h variations were induced. The results suggest that the inherent transcription modifications that give the clock its own natural rhythmicity are disrupted in rats drinking a low amount of $\mathrm{CdCl}_{2}$ in tap water. Previous studies from this laboratory indicated that chronic exposure of rats to similar low doses of $\mathrm{Cd}$ affected the circadian variation of pituitary hormone release (Lafuente et al., 2003, 2004, 2005). It seems feasible that the changes in clock gene expression in $\mathrm{MBH}$, a key region in hormone regulation, play a role in the circadian hormone disruption.
In the present study, the concomitant administration of melatonin $(3 \mu \mathrm{g} / \mathrm{mL}$; a chronobiotic-cytoprotective agent; Hardeland et al., 2011) in drinking water failed to counteract most effects of Cd on clock genes, except for Per1 expression. This suggests that the transcription modifications through which $\mathrm{CdCl}_{2}$ administration disrupts the natural rhythmicity of the circadian clock are only slightly affected by melatonin administration. A survey of the scientific literature supports an effect of melatonin on circadian clock components in the mammalian SCN (Poirel et al., 2003; Agez et al., 2007; Challet, 2007), retina (Dinet and Korf, 2007; Dinet et al., 2007), and striatal neurons in culture (Imbesi et al., 2009). In the present study, animals receiving melatonin alone showed significant phase-advances in $\mathrm{MBH}$ Per2 and Cry2 expression to peak at late afternoon and early scotophase, respectively. Again, 

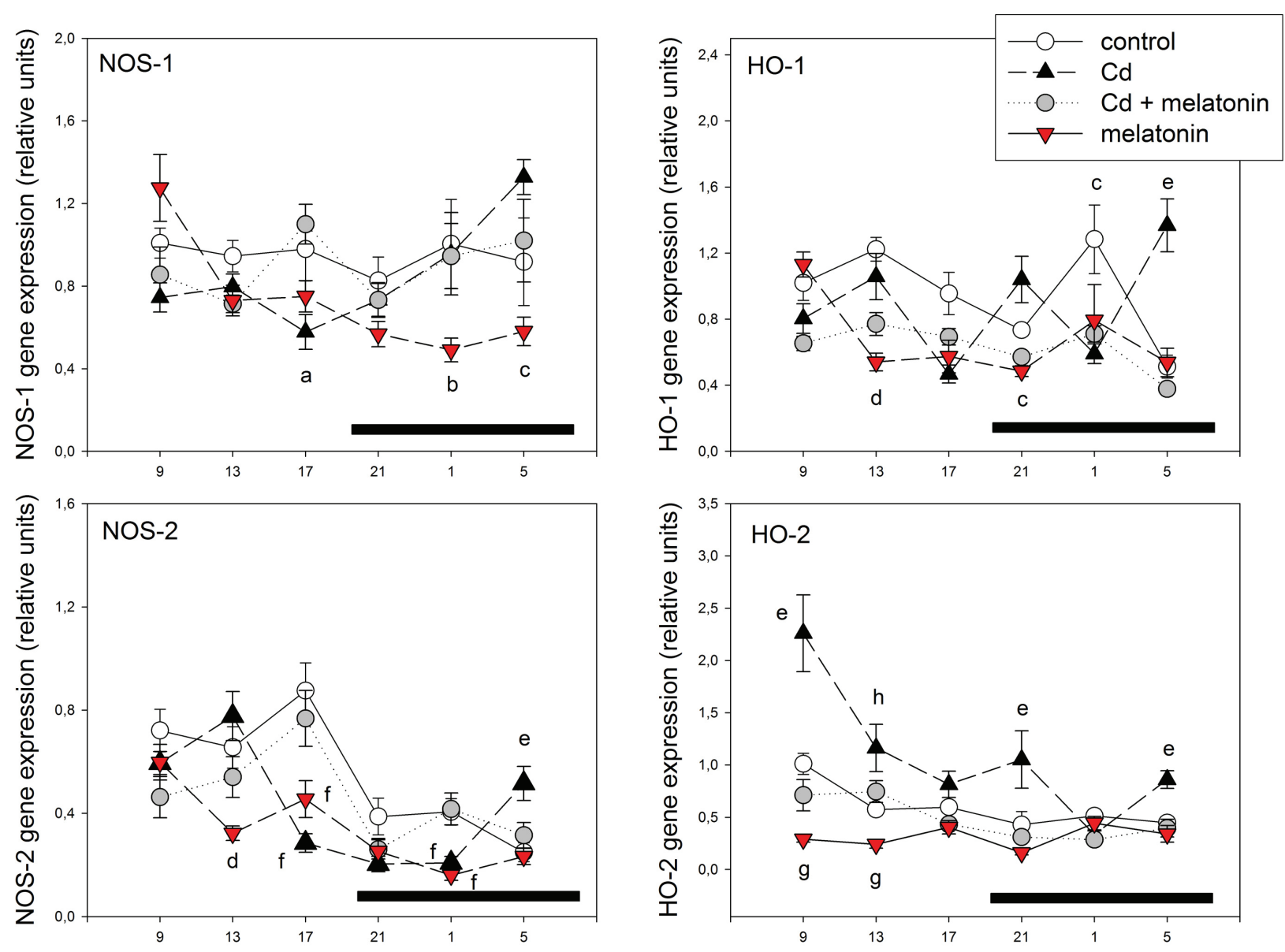

\section{Clock time}

FIGURE 3 | Effect of melatonin on Cd-induced changes in 24-h pattern of expression of mRNA for NOS-1, HO-1, NOS-2, and NOS-2 in rat MBH. For experimental details see legend to Figure 1. mRNA levels encoding the enzymes were measured as described in the text. Shown are the mean \pm SEM of mRNA determination as measured by triplicate real-time PCR analyses of RNA samples. Letters denote significant differences in a one-way ANOVA followed by a Bonferroni's multiple comparison test performed at every time interval, as follows: ${ }^{a} p<0.05$ vs. $C d+$ melatonin group; ${ }^{b} p<0.05$ vs. the remaining groups; ${ }^{\circ} p<0.02$ vs. $\mathrm{Cd} ;{ }^{d} p<0.02$ vs. control and $\mathrm{Cd}$ groups; ${ }^{e} p<0.01$ vs. the remaining groups; ${ }^{\dagger} p<0.02$ vs. control and
$\mathrm{Cd}+$ melatonin groups; ${ }^{g} p<0.01$ vs. control; ${ }^{h} p<0.01$ vs. melatonin. One-way ANOVAs within each experimental group indicated significant time-related changes in enzyme gene expression as follows: Controls: HO-1, NOS-2, and $\mathrm{HO}-2$ ( $F=7.54, p<0.001, F=10.1, p<0.0001$, and $F=5.64$, $p<0.002$, respectively). Cd: NOS-1, HO-1, NOS-2, and HO-2 ( $F=5.88$, $p<0.002, F=8.41, p<0.0001, F=18.3, p<0.0001$, and $F=7.42, p<0.001$, respectively). $\mathrm{Cd}+$ melatonin: $\mathrm{HO}-1, \mathrm{NOS}-2$, and $\mathrm{HO}-2$ ( $F=8.45, p<0.0001$, $F=6.12, p<0.002$, and $F=4.04, p<0.03$, respectively). Melatonin: NOS-1, NOS-2, and HO-1 ( $F=10.7, p<0.0001,12.9, p<0.0001$, and 5.92, $p<0.004$, respectively). For further statistical analysis, see text. the nuclear heterogeneity of the $\mathrm{MBH}$ fragments makes it impossible any valid comparison with the published effects on melatonin activity in isolated brain nuclei.

As an indication of the link between the redox status and the circadian system, 24-h variations in brain redox pathway enzymes have been described, including NOS (Ayers et al., 1996; Tunctan et al., 2002; Clemens et al., 2005), HO (Artinian et al., 2001; Rubio et al., 2003), SOD (Diaz-Munoz et al., 1985; Schaper et al., 1986; Martin et al., 2003), and catalase (Sani et al., 2006). Our present results on the circadian variation in gene expression of NOS and $\mathrm{HO}$ in $\mathrm{MBH}$ of control rats are consistent with previous publications (Jiménez-Ortega et al., 2009, 2010). In the case of the circadian rhythms in MBH mRNA levels for $\mathrm{Cu} / \mathrm{Zn}$ - and $\mathrm{Mn}-\mathrm{SOD}$ and catalase, our previous data partially disagreed with them, e.g., the late afternoon peak in $\mathrm{Cu} / \mathrm{Zn}-\mathrm{SOD}$ gene expression reported herein was only seen in one of our previous studies (JiménezOrtega et al., 2010) while the late afternoon peak in Mn-SOD was seen only as a trend in the two previous studies (Jiménez-Ortega et al., 2009, 2010).

The administration of low amount of $\mathrm{CdCl}_{2}$ brought about significant changes in 24-h variation in gene expression of $\mathrm{MBH} \mathrm{Cu} / \mathrm{Zn}-\mathrm{SOD}, \mathrm{GPx}, \mathrm{GSR}$, NOS-2, HO-1, and HO-2. The concomitant administration of melatonin prevented most of the effects of Cd on 24-h rhythmicity and overall expression of redox enzyme genes. In particular, the co-administration of melatonin and $\mathrm{CdCl}_{2}$, or the administration of melatonin alone, brought about a remarkable increase of $\mathrm{Cu} / \mathrm{Zn}-\mathrm{SOD}$ gene expression. Providing that this did reflect an increased enzyme protein activity, 

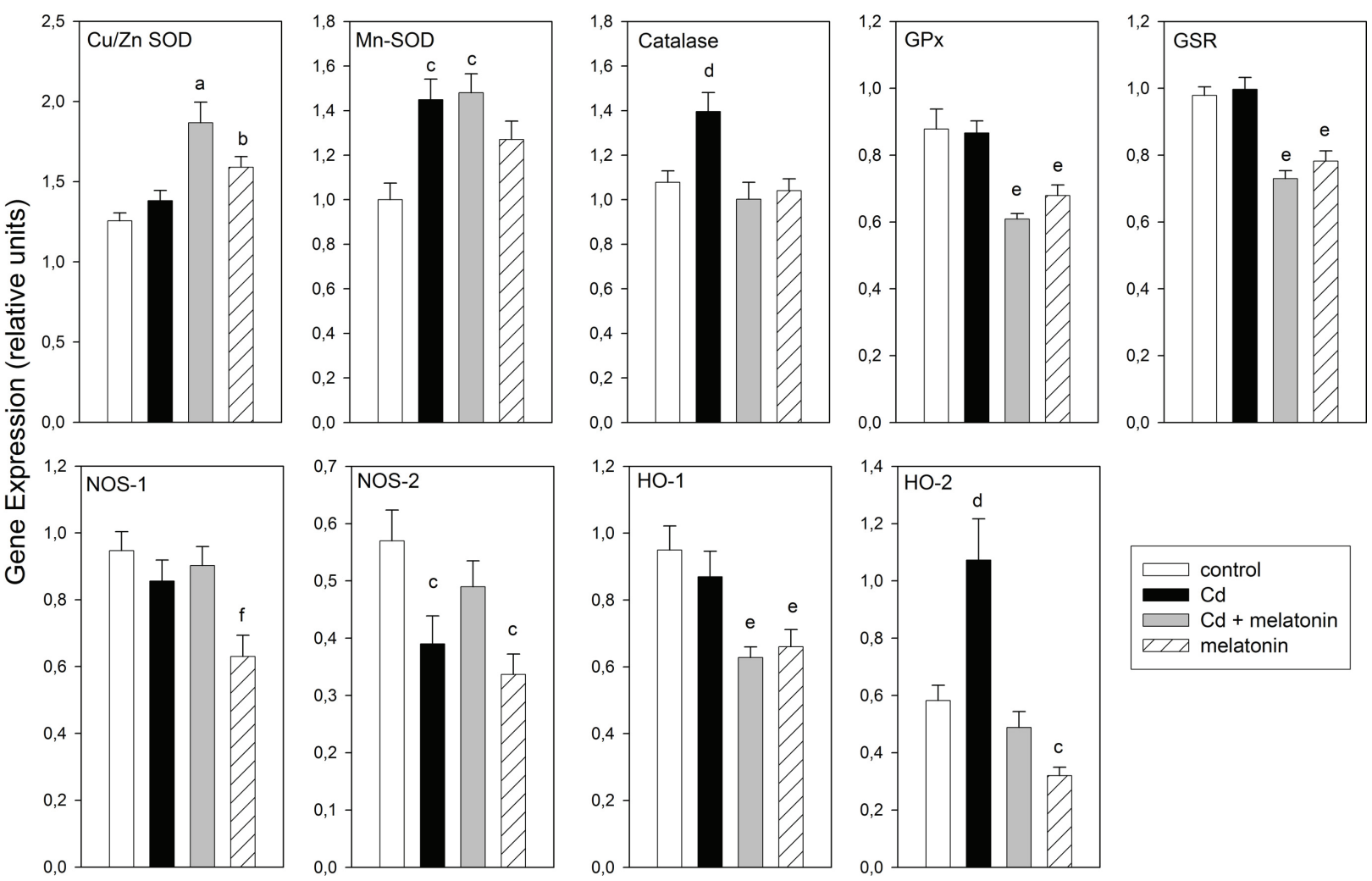

FIGURE 4 | Effect of melatonin on Cd-induced changes in mRNA of redox enzymes in rat $\mathbf{M B H}$. Shown are the mean $24 \mathrm{~h}$ values \pm SEM. For experimental details see legend to Figure 1. Letters denote significant differences in a one-way ANOVA followed by a Bonferroni's multiple comparison as follows: ${ }^{a} p<0.01$ vs. control and Cd groups; ${ }^{b} p<0.05$ vs. control; ${ }^{c} p<0.02$ vs. control; ${ }^{d} p<0.02$ vs. the remaining groups; ${ }^{e} p<0.02$ vs. control and $\mathrm{Cd}$ groups; ${ }^{\dagger} p<0.03$ vs. the remaining groups. the elevated levels of reduced glutathione expected to occur may explain, by negative feedback regulation (Griffith, 1999; Lu, 2009), the very significant decrease in MBH mRNA levels for GPx, GSR, and HO-2 found under those conditions. While some metals, like iron, copper, chromium, vanadium, or cobalt undergo redoxcycling reactions, a second group of metals including Cd, mercury, and nickel cause toxicity mainly by depleting glutathione (Wright and Baccarelli, 2007). Thus melatonin could be an effective antidote for the toxic effect of this second group of metals.

The doses of Cd employed in the present study may resemble real exposure level in active tobacco smokers, in moderately to heavily polluted areas or under occupational exposure conditions (Brzóska and Moniuszko-Jakoniuk, 2005). Under this condition, Cd intake was close to that proposed by the World Health Organization as a tolerable limit for humans $[1 \mu \mathrm{g} /$ day for a life span of 60 years (1995)]. It should be noted that because Cd absorption in the gastrointestinal tract of rats is lower than in humans, rat models simulating human exposure need to increase exposure doses to be higher than the real daily human intake of Cd (Rogalska et al., 2009).

In the present and a previous study (Jiménez-Ortega et al., 2010), a low dose of Cd differentially affects NOS-1 and NOS2 expression in $\mathrm{MBH}$ by disrupting their 24 -h pattern and by decreasing the 24-h mean mRNA levels for NOS-2. The neuronal isoform of NOS (NOS-1) is constitutively expressed in neurons whereas expression of the inducible (macrophage) isoform NOS2 occurs mainly in glial cells (Galea et al., 1992) and also in neurons (Wong et al., 1996). NOS has been detected in several hypothalamic areas including the SCN (Plano et al., 2007) and the supraoptic, paraventricular, ventromedial, and dorsomedial nuclei (Ceccatelli, 1997). NOS is also present in fibers at the median eminence, mainly in the internal layer and around blood vessels of the portal system (Knauf et al., 2001). The present results reinforce the view that the toxic effect of a low dose of $\mathrm{Cd}$ is independent on excessive NO formation. It is interesting that melatonin counteracted the generally inhibitory and disrupting effects of $\mathrm{Cd}$ on 24-h pattern of activity of NOS whereas, when administered alone, melatonin decreased gene expression of $\mathrm{MBH}$ NOS, as reported previously (Jiménez-Ortega et al., 2009) and seen again in the present series of experiments.

Heme oxygenase has an important role in controlling the redox state of the cell by functioning as a rate-limiting enzyme in the heme degradation process (Mancuso et al., 2007). Three isoforms of $\mathrm{HO}$ have been identified. HO-1 is an inducible isoform that is responsive to various stimuli, including oxidative stress. HO-2 is a constitutive isoform that is highly concentrated in the brain is less inducible by oxidative stress. The remaining isoform, $\mathrm{HO}-3$, has been less well characterized. Various hypothalamic 
nuclei displayed both HO-1 and HO-2 mRNA proteins (Ewing and Maines, 1997) and enzymatic activities (Rubio et al., 2003) explaining the high $\mathrm{CO}$ production rate that the hypothalamus exhibits (Laitinen and Juvonen, 1995). In the present study $\mathrm{CdCl}_{2}$ augmented MBH mRNA levels of HO-2 and affected the 24-h pattern of expression of both $\mathrm{HO}$ isoenzymes by inducing maxima at midday, early and late scotophase (HO-1), and at early morning (HO-2). The stimulatory effect of $\mathrm{CdCl}_{2}$ on $\mathrm{HO}-2$ mRNA reported in the present study can be interpreted in terms of an increased of oxidative load (i.e., more need of HO-1 expression).

The administration of melatonin counteracted significantly the effect of $\mathrm{Cd}$ on $24 \mathrm{~h}$ pattern in expression of both isoenzymes of HO. As shown earlier (Jiménez-Ortega et al., 2009) the inhibitory effect of melatonin on HO-1 and HO-2 mRNA is remarkable. The mechanisms involved in regulation of redox enzyme gene expression by melatonin could involve receptormediated and receptor-independent phenomena (Hardeland et al., 2011). Among the latter inhibition of radical oxygen species (ROS) generation is attractive. Since ROS play a role in cellular signaling processes, including transcription factors like nuclear factor- $\mathrm{\kappa} B$ or activator protein-1, a decrease of free radical production by melatonin would allow the repression of redox-sensitive transcription factors, which could regulate gene transcription (Lezoualc'h et al., 1998; Beni et al., 2004; Rodriguez et al., 2004).

There are a number of limitations to the present descriptive study. One important is that studies employing Western blotting analysis of clock protein levels are further needed to understand $\mathrm{Cd}$-melatonin interactions on circadian clock and redox enzyme gene expression. It should be also important to assess whether the

\section{REFERENCES}

Agez, L., Laurent, V., Pévet, P., MassonPévet, M., and Gauer, F. (2007). Melatonin affects nuclear orphan receptors mRNA in the rat suprachiasmatic nuclei. Neuroscience 144, 522-530.

Arendt, J., and Skene, D. J. (2005). Melatonin as a chronobiotic. Sleep Med. Rev. 9, 25-39.

Artinian, L. R., Ding, J. M., and Gillette, M. U. (2001). Carbon monoxide and nitric oxide: interacting messengers in muscarinic signaling to the brain's circadian clock. Exp. Neurol. 171, 293-300.

Ayers, N. A., Kapas, L., and Krueger, J. M. (1996). Circadian variation of nitric oxide synthase activity and cytosolic protein levels in rat brain. Brain Res. 707, 127-130.

Beni, S. M., Kohen, R., Reiter, R. J., Tan, D. X., and Shohami, E. (2004). Melatonin-induced neuroprotection after closed head injury is associated with increased brain antioxidants and attenuated latephase activation of NF- $\kappa$ B and AP-1. FASEB J. 18, 149-151.

Brzóska, M. M., and MoniuszkoJakoniuk, J. (2005). Bone metabolism of male rats chronically exposed

changes in amplitude as well in timing of 24-h rhythm of gene expression discussed herein can be attributed to an effect on the circadian master clock or to a masking effect on some output(s) of the clock. The nuclear heterogeneity of the MBH fragments employed is a feasible explanation for the inability to uncover some the relationships seen between clock genes in isolated brain nuclei.

Summarizing, the results support the conclusion that the interfering effect of melatonin on the activity of a low dose of Cd on 24-h rhythms of MBH clock and redox enzyme genes is mainly exerted at the level of redox enzyme gene expression. Since most of published studies on neuroprotective activity of melatonin were performed by measuring specific targets at single time points, generally at morning hours, and in view of the 24-h changes in redox state that occurs in a number of tissues (Hardeland et al., 2003; Subramanian et al., 2008), it should be important to include a chronopharmacological approach for the full analysis of the above mentioned effects of melatonin.

\section{ACKNOWLEDGMENTS}

This work was supported by grants from Fondo de Investigaciones Sanitarias (FIS-PI05-0163), Madrid, Programa de Creación y Consolidación de Grupos de Investigación Universidad Complutense-Comunidad de Madrid (CCG08-UCM/SAL4188), Agencia Nacional de Promoción Científica y Tecnológica, Argentina (PICT 2007-01045) and the University of Buenos Aires (M 006). Daniel P. Cardinali is a Research Career Awardee from the Argentine Research Council (CONICET) and Professor Emeritus, University of Buenos Aires. Pablo A. Scacchi is a postdoctoral fellow from CONICET.

glutathione cycle and superoxide dismutase activity. Neuroscience 16, 859-863.

Dinet, V., Ansari, N., Torres-Farfan, C., and Korf, H. W. (2007). Clock gene expression in the retina of melatonin-proficient $(\mathrm{C} 3 \mathrm{H})$ and melatonin-deficient (C57BL) mice. J. Pineal Res. 42, 83-91.

Dinet, V., and Korf, H. W. (2007). Impact of melatonin receptors on pCREB and clock-gene protein levels in the murine retina. Cell Tissue Res. 330, 29-34.

Ewing, J. F., and Maines, M. D. (1997). Histochemical localization of heme oxygenase-2 protein and mRNA expression in rat brain. Brain Res. Brain Res. Protoc. 1, 165-174.

Galea, E., Feinstein, D. L., and Reis, D. J. (1992). Induction of calciumindependent nitric oxide synthase activity in primary rat glial cultures. Proc. Natl. Acad. Sci. U.S.A. 89, 10945-10949.

Griffith, O. W. (1999). Biologic and pharmacologic regulation of mammalian glutathione synthesis. Free Radic. Biol. Med. 27, 922-935.

Hardeland, R., Cardinali, D. P., Srinivasan, V., Spence, D. W., Brown, G. M., and Pandi-Perumal, S. R.
(2011). Melatonin - a pleiotropic, orchestrating regulator molecule. Prog. Neurobiol. 93, 350-384.

Hardeland, R., Coto-Montes, A., and Poeggeler, B. (2003). Circadian rhythms, oxidative stress, and antioxidative defense mechanisms. Chronobiol. Int. 20, 921-962.

Hirayama, J., Cho, S., and SassoneCorsi, P. (2007). Circadian control by the reduction/oxidation pathway: catalase represses lightdependent clock gene expression in the zebrafish. Proc. Natl. Acad. Sci. U.S.A. 104, 15747-15752.

Imbesi, M., Arslan, A. D., Yildiz, S., Sharma, R., Gavin, D., Tun, N., Manev, H., and Uz, T. (2009). The melatonin receptor MT1 is required for the differential regulatory actions of melatonin on neuronal "clock" gene expression in striatal neurons in vitro. J. Pineal Res. 46, 87-94.

Institute of Laboratory Animal Resources, C. o. L. S. N. R. C. (1996). Guide for the Care and Use of Laboratory Animals. Washington, DC: National Academy Press.

Iovanna, J., Dusetti, N., Calvo, E., and Cardinali, D. P. (1990). Diurnal changes in actin mRNA levels and incorporation of 35S-methionine 
into actin in the rat hypothalamus. Cell. Mol. Neurobiol. 10, 207-216.

Jiménez-Ortega, V., Cano, P., Cardinali, D. P., and Esquifino, A. I. (2009). 24-Hour variation in gene expression of redox pathway enzymes in rat hypothalamus: effect of melatonin treatment. Redox Rep. 14, 132-138.

Jiménez-Ortega, V., Cardinali, D. P., Fernández-Mateos, M. P., RiosLugo, M. J., Scacchi, P. A., and Esquifino, A. I. (2010). Effect of cadmium on 24-hour pattern in expression of redox enzyme and clock genes in medial basal hypothalamus. Biometals 23, 327-337.

Knauf, C., Ferreira, S., Hamdane, M., Mailliot, C., Prevot, V., Beauvillain, J. C., and Croix, D. (2001). Variation of endothelial nitric oxide synthase synthesis in the median eminence during the rat estrous cycle: an additional argument for the implication of vascular blood vessel in the control of GnRH release. Endocrinology $142,4288-4294$.

Lafuente, A., Gonzalez-Carracedo, A., Romero, A., Cano, P., and Esquifino, A. I. (2004). Cadmium exposure differentially modifies the circadian patterns of norepinephrine at the median eminence and plasma $\mathrm{LH}$, FSH and testosterone levels. Toxicol. Lett. 146, 175-182.

Lafuente, A., Gonzalez-Carracedo, A., Romero, A., Cano, P., and Esquifino, A. I. (2005). Cadmium exposure differentially modifies the circadian patterns of norepinephrine at the median eminence and plasma $\mathrm{LH}$, FSH and testosterone levels. Toxicol. Lett. 146, 175-182.

Lafuente, A., Gonzalez-Carracedo, A., Romero, A., and Esquifino, A. I. (2003). Effect of cadmium on 24-h variations in hypothalamic dopamine and serotonin metabolism in adult male rats. Exp. Brain Res. 149, 200-206.

Laitinen, J. T., and Juvonen, R. O. (1995). A sensitive microassay reveals marked regional differences in the capacity of rat brain to generate carbon monoxide. Brain Res. 694, 246-252.

Leret, M. L., Millan, J. A., and Antonio, M. T. (2003). Perinatal exposure to lead and cadmium affects anxietylike behaviour. Toxicology 186, 125130.

Levi, F., Okyar, A., Dulong, S., Innominato, P. F., and Clairambault, J. (2010). Circadian timing in cancer treatments. Annu. Rev. Pharmacol. Toxicol. 50, 377-421.

Lezoualc'h, F., Sparapani, M., and Behl, C. (1998). N-acetyl-serotonin (normelatonin) and melatonin protect neurons against oxidative challenges and suppress the activity of the transcription factor NF-кB. J. Pineal Res. 24, 168-178.

Lincoln, G. A., Clarke, I. J., Hut, R. A., and Hazlerigg, D. G. (2006). Characterizing a mammalian circannual pacemaker. Science 314, 1941-1944.

Livak, K. J., and Schmittgen, T. D. (2001). Analysis of relative gene expression data using real-time quantitative PCR and the $2^{-\Delta \Delta} \mathrm{Ct}$ method. Methods 25, 402-408.

Lopez, E., Arce, C., Oset-Gasque, M. J., Canadas, S., and Gonzalez, M. P. (2006). Cadmium induces reactive oxygen species generation and lipid peroxidation in cortical neurons in culture. Free Radic. Biol. Med. 40, 940-951.

Lu, S. C. (2009). Regulation of glutathione synthesis. Mol. Aspects Med. 30, 42-59.

Mancuso, C., Scapagini, G., Curro, D., Giuffrida Stella, A. M., De Marco, C., Butterfield, D. A., and Calabrese, V. (2007). Mitochondrial dysfunction, free radical generation and cellular stress response in neurodegenerative disorders. Front. Biosci. 12, 1107-1123.

Martin, V., Sainz, R. M., Mayo, J. C., Antolin, I., Herrera, F., and Rodriguez, C. (2003). Daily rhythm of gene expression in rat superoxide dismutases. Endocr. Res. 29, 83-95.

Moreno, M. L., Villanua, M. A., and Esquifino, A. I. (1992). Serum prolactin and luteinizing hormone levels and the activities of hypothalamic monoamine oxidase $\mathrm{A}$ and $\mathrm{B}$ and phenylethanolamine- $N$-methyl transferase are changed during sexual maturation in male rats treated neonatally with melatonin. J. Pineal Res. 13, 167-173.

Pandi-Perumal, S. R., Srinivasan, V., Maestroni, G. J. M., Cardinali, D. P., Poeggeler, B., and Hardeland, R. (2006). Melatonin: nature's most versatile biological signal? FEBS $J$. 273, 2813-2838.

Plano, S. A., Agostino, P. V., and Golombek, D. A. (2007). Extracellular nitric oxide signaling in the hamster biological clock. FEBS Lett. 581, 5500-5504.

Poirel, V. J., Boggio, V., Dardente, H., Pevet, P., Masson-Pevet, M., and Gauer, F. (2003). Contrary to other non-photic cues, acute melatonin injection does not induce immediate changes of clock gene mRNA expression in the rat suprachiasmatic nuclei. Neuroscience 120, 745-755.

Reiter, R. J., Paredes, S. D., Manchester, L. C., and Tan, D. X. (2009).
Reducing oxidative/nitrosative stress: a newly-discovered genre for melatonin. Crit. Rev. Biochem. Mol. Biol. 44, 175-200.

Rodriguez, C., Mayo, J. C., Sainz, R. M. Antolin, I., Herrera, F., Martin, V., and Reiter, R. J. (2004). Regulation of antioxidant enzymes: a significant role for melatonin. J. Pineal Res. 36, 1-9.

Rogalska, J., Brzóska, M. M. Roszczenko, A., and MoniuszkoJakoniuk, J. (2009). Enhanced zinc consumption prevents cadmium induced alterations in lipid metabolism in male rats. Chem. Biol. Interact. 177, 142-152.

Rubio, M. F., Agostino, P. V., Ferreyra, G. A., and Golombek, D. A. (2003). Circadian heme oxygenase activity in the hamster suprachiasmatic nuclei. Neurosci. Lett. 353, 9-12.

Rutter, J., Reick, M., and McKnight, S. L. (2002). Metabolism and the control of circadian rhythms. Annu. Rev. Biochem. 71, 307-331.

Sani, M., Sebai, H., Gadacha, W., Boughattas, N. A., Reinberg, A., and Mossadok, B. A. (2006). Catalase activity and rhythmic patterns in mouse brain, kidney and liver. Comp. Biochem. Physiol. B. Biochem. Mol. Biol. 145, 331-337.

Satarug, S., Baker, J. R., Urbenjapol, S., Haswell-Elkins, M., Reilly, P. E., Williams, D. J., and Moore, M. R. (2003). A global perspective on cadmium pollution and toxicity in nonoccupationally exposed population. Toxicol. Lett. 137, 65-83.

Schaper, U., Holig, K., Weber, A., and Scheuch, D. W. (1986). Diurnal variations in superoxide dismutase (EC 1.15.1.1) activity and malondialdehyde concentration in the rat brain and striatum. Z. Med. Lab. Diagn. 27, 50-51.

Subramanian, P., Dakshayani, K., PandiPerumal, S. R., Trakht, I., and Cardinali, D. P. (2008). 24-Hour rhythms in oxidative stress during hepatocarcinogenesis in rats: effect of melatonin or á-ketoglutarate. Redox Rep. $13,78-86$.

Sugita, M., and Tsuchiya, K. (1995). Estimation of variation among individuals of biological half-time of cadmium calculated from accumulation data. Environ. Res. 68, 31-37.

Szentagothai, B., Flerkó, B., Mess, B., and Halász, B. (1968). Hypothalamic Control of the Anterior Pituitary, 3rd Edn. Budapest: Akademíai Kiadó.

Tunctan, B., Weigl, Y., Dotan, A., Peleg, L., Zengil, H., Ashkenazi, I., and Abacioglu, N. (2002). Circadian variation of nitric oxide synthase activity in mouse tissue. Chronobiol. Int. 19, 393-404.

Viaene, M. K., Masschelein, R., Leenders, J., De, G. M., Swerts, L. J., and Roels, H. A. (2000). Neurobehavioural effects of occupational exposure to cadmium: a cross sectional epidemiological study. Occup. Environ. Med. 57, 19-27.

Wakabayashi, I., Hatake, K., Kimura, N., Kakishita, E., and Nagai, K. (1987). Modulation of vascular tonus by the endothelium in experimental diabetes. Life Sci. 40, 643-648.

WHO. (1995). "Inorganic constituents and physical parameters," in Guidelines for Drinking Water-Quality: Health Criteria and other Supporting Information (Geneva: World Health Organization).

Wong, M. L., Rettori, V., Al-Shekhlee, A., Bongiorno, P. B., Canteros, G., McCann, S. M., Gold, P. W., and Licinio, J. (1996). Inducible nitric oxide synthase gene expression in the brain during systemic inflammation. Nat. Med. 2, 581-584.

Wright, R. O., and Baccarelli, A. (2007). Metals and neurotoxicology. J. Nutr. 137, 2809-2813.

Yang, Z., Yang, S., Qian, S. Y., Hong, J. S., Kadiiska, M. B., Tennant, R. W. Waalkes, M. P., and Liu, J. (2007). Cadmium-induced toxicity in rat primary mid-brain neuroglia cultures: role of oxidative stress from microglia. Toxicol. Sci. 98, 488-494.

Conflict of Interest Statement: The authors declare that the research was conducted in the absence of any commercial or financial relationships that could be construed as a potential conflict of interest.

Received: 12 January 2011; accepted: 24 February 2011; published online: 16 March 2011.

Citation: Jiménez-Ortega V, CanoBarquilla $P$, Scacchi PA, Cardinali DP and Esquifino AI (2011) Cadmiuminduced disruption in 24- $h$ expression of clock and redox enzyme genes in rat medial basal hypothalamus: prevention by melatonin. Front. Neur. 2:13. doi 10.3389/fneur.2011.00013

This article was submitted to Frontiers in Sleep and Chronobiology, a specialty of Frontiers in Neurology.

Copyright (C) 2011 Jiménez-Ortega, Cano-Barquilla, Scacchi, Cardinali and Esquifino. This is an open-access article subject to an exclusive license agreement between the authors and Frontiers Media $S A$, which permits unrestricted use, distribution, and reproduction in any medium, provided the original authors and source are credited. 